\title{
Assessment of Implementation of a CAMBRA-Based Program in a Dental School Environment
}

\author{
Sorin T. Teich, D.M.D., M.B.A.; Catherine Demko, Ph.D.; Wisam Al-Rawi, D.M.D.; \\ Tom Gutberg, B.Sc.
}

Abstract: Caries development is determined by a balance of protective and pathological factors, so the clinician should be able to identify and document those factors, understand their relative weight in disease development or reversal, and make recommendations to patients that will lead to risk reduction. The caries management by risk assessment (CAMBRA) protocol frames these factors into an easy-to-follow template that also guides the clinician in making recommendations. The purposes of this study were to examine implementation of the CAMBRA-based risk assessment program in a predoctoral clinic at one dental school, assess the accuracy of caries risk evaluation by the students, and evaluate the utilization of professionally applied fluoride varnish in a moderate- and high-risk patient cohort. After dental clinic patients were screened for previous caries risk status, sixty-eight moderate- or high-risk patients were invited to participate in the study. At the study visit that included four bite-wing radiographs, a new caries risk assessment (CRA) form was completed. Our results showed that students underestimated the risk in 25 percent of the cases; the underestimation occurred especially when visible cavitation or caries into dentin by radiograph was the only risk factor or when caries were not identified at the initial visit when the CRA form was completed for the first time despite the presence of other high-risk factors. Students also underestimated both risk and protective factors at the initial evaluation visit compared with the study visit. The results show that students were not rigorous enough in documenting these factors and determining the patient's risk. In order to increase the sensitivity of risk assessment, training and recalibration for students and faculty members should be an ongoing process.

Dr. Teich is Associate Professor and Assistant Dean of Clinical Operations, Department of Comprehensive Care, School of Dental Medicine, Case Western Reserve University; Dr. Demko is Associate Professor, Department of Community Dentistry, School of Dental Medicine, Case Western Reserve University; Dr. Al-Rawi is Clinical Assistant Professor, School of Dentistry, University of Michigan; and Mr. Gutberg is a senior dental student, School of Dental Medicine, Case Western Reserve University. Direct correspondence and requests for reprints to Dr. Sorin T. Teich, Department of Comprehensive Care, School of Dental Medicine, Case Western Reserve University, 2124 Cornell Rd., Cleveland, OH 44106; 216-368-6161; Sorin@ case.edu.

Keywords: clinical education, clinical teaching, dental education, caries, dental caries, CAMBRA, fluoride, risk assessment

Submitted for publication 3/14/12; accepted 6/19/12

$\mathrm{T}$ he value of prevention is widely recognized by the dental profession, and teaching this topic has become a foundational principle and integral part of predoctoral dental curricula. ${ }^{1}$ While the basic scientific principles that lead to understanding oral disease development have been identified, translation of these principles into practice may pose significant challenges during students' training and in practice. Since 1995, risk-based prevention of dental caries has been promoted, ${ }^{2}$ and algorithms aimed at helping clinicians determine a patient's risk level have been developed. ${ }^{3}$

One study found that clinical protocols for caries risk assessment and prevention can be implemented in dental education and that students feel training and practice of caries prevention should be increased. ${ }^{4}$ A recent survey of North American dental schools found that caries risk assessment has been incorporated into clinical caries manage- ment curricula in 68 percent of those institutions. ${ }^{5,6}$ Despite significant progress toward developing and implementing evidence-based caries risk assessment and management programs in U.S. dental schools, however, wide variations in interpretation and application of these programs exist. ${ }^{7}$

Tools for caries risk assessment have been tested in educational settings, with varying results. Only 45 percent of the students in one study agreed that the Cariogram tool developed in Sweden was easy to understand, and only 36 percent agreed it was easy to apply; 82 percent said they will not use this tool in clinical practice. ${ }^{8}$ Another study found that only 60 percent of full-time and 33 percent of part-time faculty members were knowledgeable about Cariogram use. ${ }^{9}$ In contrast, most students in another study agreed that the caries-risk assessment tool (CAT) developed by the American Academy of Pediatric Dentistry ${ }^{10}$ was useful for determining 
preventive procedures, and 80 percent indicated they were likely to use it in clinical practice. ${ }^{11}$ Another tool (the International Caries Detection and Assessment System, ICDAS $)^{12}$ was found to improve the diagnostic skills of students when they tried to detect occlusal carious lesions. ${ }^{13}$

The concept of caries management by risk assessment (CAMBRA) was developed by a consortium of dental-related organizations. ${ }^{14}$ Guidelines for clinical implementation of risk determination and for therapeutic recommendations driven by risk were published in three articles. ${ }^{15-17}$ Since caries development is determined by a balance of protective and pathological factors, ${ }^{18}$ the clinician should be able to identify and document these factors, understand their relative weight in disease development or reversal, and provide recommendations to patients that will lead to risk reduction. The CAMBRA protocol aims to frame these factors into an easy-to-follow template $^{14,15}$ that will also guide the clinician in making recommendations to patients. ${ }^{16,17}$

Although many dental schools have embraced the CAMBRA concept, integrating it into dental education is not without challenges. Students have reported limited confidence in using the protocol with children younger than five years $;^{6}$ training and calibrating students and faculty members are difficult $;{ }^{19}$ risk assessment factors are dependent on the caries prevalence of the population; ${ }^{19-21}$ and reimbursement for CAMBRA-related procedures is low or nonexistent. ${ }^{22}$ Many dental schools provide access to care to underserved, low socioeconomic populations, and prevention costs generated by caries risk assessments can reach an annual amount up to $\$ 1,117$ for a high-risk patient. ${ }^{23}$ Because caries is more prevalent in lower socioeconomic groups, ${ }^{24,25}$ the increased prevention costs pose another hurdle in implementing these protocols in educational and other institutions that provide care for these patients.

The concept of caries risk assessment and prevention has also not been fully adopted in general practice. The majority of dentists surveyed in a U.S. dental network reported performing caries risk assessment (CRA) for children, but only 14 percent reported assessing risk using a special form. ${ }^{26}$ Only 69 percent of the network dentists evaluated adult patients with CRA, and only 57 percent of these patients received individualized caries prevention. ${ }^{27}$ Another survey in the United States found that 72 percent of the responding dentists performed some type of risk assessment, but only 27 percent documented the outcome and only 51 percent provided a management plan based on the patient's risk status. ${ }^{3}$ It is clear that enhancing caries prevention education in predoctoral curricula will have a larger effect on the profession as the graduates join residencies and practices.

A CAMBRA-based CRA program has been gradually implemented since 2008 as part of the didactic and clinical curriculum at Case Western Reserve University School of Dental Medicine. The clinical use of a standardized form to characterize a patient's risk for caries helps the faculty and students to determine individualized preventive therapeutic intervention as part of the treatment planning process. The purposes of this study were to examine the implementation of the CAMBRA-based risk assessment program in the predoctoral clinic, assess the accuracy of caries risk evaluation by students, and evaluate the utilization of professionally applied fluoride varnish in a moderate- and high-risk patient cohort.

\section{Methods}

The faculty adopted a modified version of the CRA form from the American Dental Association (ADA). ${ }^{28}$ The form (Figures 1 and 2) includes a list of caries risk and protective factors, instructions that help determine the risks, and caries preventive recommendations aligned with the CAMBRA protocol. ${ }^{15-17}$ Students are required to complete the CRA form as a baseline for their patients before starting treatment. Fluoride varnish is indicated according to patient risk as described on the form. Students are trained regarding CRA in the second year in classroom lectures and in the clinic with families of patients for whom they have to assess risk. Additional training is provided during clinical orientation at the beginning of the junior year. Faculty members who supervise determination of patients' caries risk status (CRS) as part of the comprehensive care predoctoral clinic receive periodic in-house training in departmental seminars.

For this study, initial CRA forms were completed by all junior and senior students for their assigned patients between July 2008 and May 2010, and each patient's CRS and fluoride varnish receipt were entered into the patient's electronic dental record. The appointment during which the form was completed for the first time as part of the standard patient evaluation in the comprehensive care predoctoral clinic was denoted the "initial visit." Over a two-month period (June-July 2010), consecutively scheduled 


\section{Caries risk assessment form}

\section{Use CDT code D0160 for initial exam and D0170 for recall}

\begin{tabular}{|l|l|l|}
\hline Student & Name: & ID\#: \\
\hline Patient & Name: & Chart\#: \\
\hline
\end{tabular}

\begin{tabular}{|l|c|c|}
\hline Date: & First evaluation appointment $\square$ & Recall appointment $\square$ \\
\hline
\end{tabular}

\begin{tabular}{|c|c|c|c|c|}
\hline \multicolumn{5}{|c|}{ High risk factors } \\
\hline & & Yes & No & Notes \\
\hline A & $\begin{array}{l}\text { Visible cavitations (carious) or caries into dentin } \\
\text { by radiograph }\end{array}$ & & & \\
\hline B & Caries restored in last 3 years & & & \\
\hline $\mathrm{C}$ & Readily visible heavy plaque on teeth & & & \\
\hline $\mathrm{D}$ & $\begin{array}{l}\text { Frequent ( } \geq 3 \text { times daily) between meals snacks } \\
\text { of sugar/cooked starch }\end{array}$ & & & \\
\hline E & $\begin{array}{l}\text { Saliva reducing factors } \\
\text { - Hyposalivatory medications } \\
\text { - Radiation to head and neck } \\
\text { - Systemic reasons, e.g. Sjogren syndrome }\end{array}$ & & & \\
\hline $\mathrm{F}$ & Visually inadequate saliva flow & & & \\
\hline $\mathrm{G}$ & $\begin{array}{l}\text { Appliances present, fixed or removable: e.g. } \\
\text { orthodontic brackets/bands/retainer or removable } \\
\text { partial denture(s) or FPD or adhesively retained } \\
\text { FPD }\end{array}$ & & & \\
\hline & $\begin{array}{l}\text { If YES to A and hyposalivation confirmed - perfo } \\
\text { and define patient as Extreme High Risk }\end{array}$ & & & ulture (CDT code D0415) \\
\hline & $\begin{array}{l}\text { If YES to A, or any two of B-G, perform bacterial } \\
\text { patient as High Risk }\end{array}$ & culture & & code D0415) and define \\
\hline$\bullet$ & $\begin{array}{l}\text { If YES to F, measure saliva flow (CDT code D04 } \\
\text { hyposalivation } \rightarrow \text { define patient as High Risk }\end{array}$ & $5-1)$ & & $\mathrm{ml} / \mathrm{min}$ by test $=$ \\
\hline - & If YES to $\mathrm{G}$ only, define patient as Moderate Risl & & & \\
\hline
\end{tabular}

\begin{tabular}{|l|l|l|l|l|}
\hline \multicolumn{5}{|c|}{ Moderate risk factors } \\
\hline & \multicolumn{1}{|c|}{ Yes } & No & Notes \\
\hline A & Exposed roots & & & \\
\hline B & Deep pits and fissures / developmental defects & & & \\
\hline C & Interproximal enamel lesions/radiolucencies & & & \\
\hline D & $\begin{array}{l}\text { Enamel white spots lesions or occlusal } \\
\text { discoloration }\end{array}$ & & & \\
\hline E & Use of recreational dnugs & & & \\
\hline
\end{tabular}

Patient declines bacterial culture and/or salivary flow test

$\square$

Patient signature (for test decline only)
Faculty ID\# and name

Date

Faculty signature

Form should not be signed by faculty unless risk assessment and recommendations sections are completed

Figure 1. First page of the CRA form 


\begin{tabular}{|l|l|l|l|l|}
\hline \multicolumn{5}{|c|}{ Protective factors } \\
\hline & \multicolumn{1}{|c|}{ Yes } & No & Notes \\
\hline A & $\begin{array}{l}\text { Salivary flow visually adequate or } \geq 1 \mathrm{ml} / \mathrm{min} \\
\text { by test }\end{array}$ & & & \\
\hline B & Lives in fluoridated community & & & \\
\hline C & Uses fluoride toothpaste daily & & & \\
\hline D & Uses fluoride mouthwash/rinse/gel daily & & & $\bullet$ Brand \\
\hline E & Uses xylitol gum or mints 4x/day & & & $\bullet$ Brand \\
\hline F & Uses Chlorhexidine rinse & & & $\bullet$ Brand \\
\hline
\end{tabular}

\begin{tabular}{|c|c|c|c|}
\hline \multicolumn{4}{|c|}{ Caries Risk Assessment } \\
\hline Low risk $\square$ & Moderate risk $\square$ & High risk $\square$ & Extreme risk $\square$ \\
\hline \multicolumn{4}{|c|}{ Recall schedule } \\
\hline 12 months $\square$ & 6 months $\square$ & 4 months $\square$ & 3 months $\square$ \\
\hline \multicolumn{4}{|c|}{ Bitewings recommended } \\
\hline 24 months $\square$ & 18 months $\square$ & 12 months $\square$ & 6 months $\square$ \\
\hline
\end{tabular}

\begin{tabular}{|c|c|}
\hline \multicolumn{2}{|l|}{ Recommendations given (check all that apply) } \\
\hline & CDT code \\
\hline Low risk & \\
\hline Nutritional counseling for control of dental disease & D1310 \\
\hline OTC fluoride-containing toothpaste $2 \mathrm{x} /$ day & \\
\hline Moderate risk - all of the above and: & \\
\hline OTC $0.05 \% \mathrm{NaF}$ rinse daily & \\
\hline OTC Xylitol gum or candies - 2 gums/candies, $4 \mathrm{x} /$ day & \\
\hline $\begin{array}{l}\text { Application of } 5 \% \mathrm{NaF} \text { varnish (at least twice during the restorative treatment } \\
\text { sequence) }\end{array}$ & D1206 \\
\hline High risk - all of the above and: & \\
\hline Chlorhexidine $0.12 \%, 10 \mathrm{ml} ., 1 \mathrm{x} / \mathrm{day}$, one week per month & \\
\hline Replace OTC regular fluoride toothpaste with $1.1 \% \mathrm{NaF}$ toothpaste $2 \mathrm{x} /$ day & \\
\hline Extreme risk - all of the above and: & \\
\hline $\begin{array}{l}\text { OTC } 0.05 \% \mathrm{NaF} \text { rinse when mouth feels dry, after snacking, breakfast and } \\
\text { lunch. }\end{array}$ & \\
\hline Baking soda gum as needed & \\
\hline $\begin{array}{l}\text { Acid-buffering rinses as needed if mouth feels dry, after snacking, bedtime } \\
\text { and after breakfast }\end{array}$ & \\
\hline Calcium/Phosphate paste with Recaldent 2x/day & \\
\hline
\end{tabular}

-For extreme risk - use Chlorhexidine in water base

CAMBRA publications - http://www.cdafoundation.org/who_we_are/publications/cda_journal_october_2007

See also the Clinic Manual -

http://dental.case.edu/wikifiles/CariesRiskAssessment.pdf,

http://dental.case.edu/wikifiles/RiskAssessProtocol.pdf.

http://dental.case.edu/wikifiles/RiskAssessProducts.pdf

Figure 2. Second page of the CRA form 
patients in the predoctoral clinic were screened for previous caries risk status in their dental record, and only moderate- or high-risk patients (as determined at the initial visit) were invited to participate in the study. The CRA forms filled out at the initial visit by the students assigned to provide comprehensive treatment were reassessed, and the CRS was recorded in a database. These forms were reevaluated by one of the authors (STT) after the patients were enrolled in the study, and the CRS was redetermined based on the risk factors mentioned on the form.

The visit during which the patients were enrolled is called in this article the "study visit." At the study visit, which included four bite-wing radiographs, a new CRA form was completed by two sophomore students under the supervision of two faculty members (STT and WAR). Following completion of the CRA forms, the CRS was determined by one of the authors (STT). Unpaired comparisons between groups were tested using the Mann-Whitney or Student's t-test; paired comparisons were tested using the Wilcoxen signed-rank test. The level of significance for all testing was $\alpha=0.05$. The study protocol was approved by the university's Institutional Review Board; patients signed an informed consent to participate in the study.

\section{Results}

Sixty-eight patients with at least moderate caries risk were enrolled in the study for assessment of their follow-up CRA. Enrolled patients were at least eighteen years of age, averaging 57.7 years (Table 1). The study visit occurred on average 12.2 months after the initial visit ( $\mathrm{SD}=8.1$ months). Only thirty patients out of sixty-eight enrolled (44.1 percent) received fluoride varnish, despite the fact that our protocol requires that all moderate-risk and high-risk patients receive it.

After we reviewed the CRA forms completed at the initial visit by the student dentists (initial
CRA), it became apparent that the information on the CRA forms was not used as intended to produce an accurate initial CRS. When the CRA form algorithm was correctly reapplied to the available data on the forms, 25 percent (17/68) of the initial CRS were recategorized as high from the initial moderate category. Underestimates occurred most often when caries were not identified at the initial visit or when current caries was the only high-risk factor (Figure 3). Following the results of reapplying the CRA algorithm on the initial CRA forms, it was determined that the moderate-risk group was too small (eight patients) compared with the high-risk group (sixty patients); therefore, we decided to reclassify the patients for statistical analysis according to their detectable caries status at the study visit (Table 1).

High-risk, moderate-risk, and protective factors at the study visit are summarized in Figures 4, 5 , and 6 . The red columns denote patients who had detectable caries in dentin at the study visit (Caries+), whereas the blue columns represent patients without detectable caries in dentin at the study visit (Caries-). Comparing the different factors for the Caries+ and Caries- groups using the Mann-Whitney test showed that the single statistically significant difference was the presence of interproximal incipient lesions/ radiolucencies confined to enamel that were more prevalent in the Caries+ group (Figure 5).

The risk and protective factors documented at the initial and study visits were compared for the total pool of patients, stratifying the pool by patients who received fluoride varnish $(\mathrm{FV}+)$ or did not receive fluoride varnish (FV-) after the initial evaluation and also stratified by detectable caries at study visit (Caries+ vs. Caries- groups). The results showed that, in almost all categories, the students' documentation on the initial CRA forms underestimated both risk and protective factors compared with the number of factors identified during the study visit (Table 2 ). Between the initial visit and the study visit, the number of risk factors documented increased, regardless of fluoride varnish application or the presence of

Table 1. Study participant groups by detectable caries at study visit

\begin{tabular}{lccc} 
Characteristic & Caries + & Caries - & Total \\
\hline Subjects & 29 & 39 & 68 \\
Females (\%) & $16(55.2 \%)$ & $20(51.3 \%)$ & $36(52.9 \%)$ \\
Months between initial visit and study visit (mean, sd) & $11.5(8.7)$ & $12.7(7.7)$ & $12.2(8.1)$ \\
Age (mean, sd) & $57.9(14.8)$ & $57.6(14.4)$ & $57.7(14.5)$ \\
Fluoride varnish & $13(44.8 \%)$ & $17(43.6 \%)$ & $30(44.1 \%)$
\end{tabular}




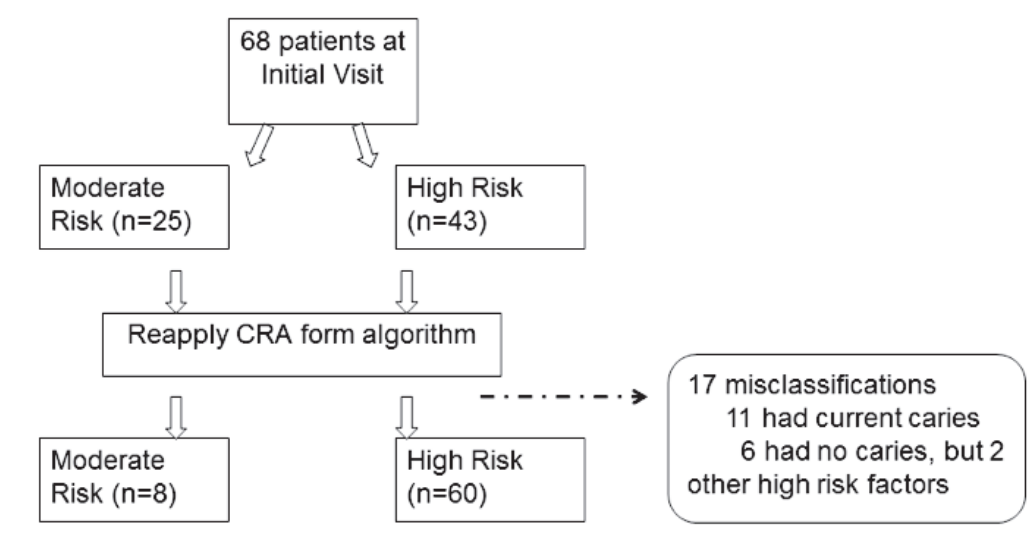

Figure 3. Faculty review of CRA forms from initial visit and reclassification of patients' caries risk status

detectable caries at the study visit. The same trend also was observed for a number of protective factors, except for the group that received fluoride varnish. The consistent increase in protective and risk factors was observed regardless of how patients were stratified, i.e., presence or absence of prior fluoride varnish and presence or absence of caries at the study visit.

\section{Discussion}

While current evidence suggests that the paradigm shift to prevention has not been universally implemented, ${ }^{1}$ integration of caries risk determination and prevention strategies in dental curricula provide opportunities to translate scientific evidence into better patient care. Our results show that students incorrectly used the risk assessment algorithm on the CRA form and underestimated the risk in 25 percent of the cases. The underestimation occurred especially when "visible cavitation or caries into dentin by radiograph" was the only risk factor or when caries were not identified at the initial visit, despite the presence of other high-risk factors. This finding is of special interest because visible cavitation has been reported as one parameter that is an obvious sign of high caries risk. ${ }^{19}$

\section{High Risk Factors at Study Visit}

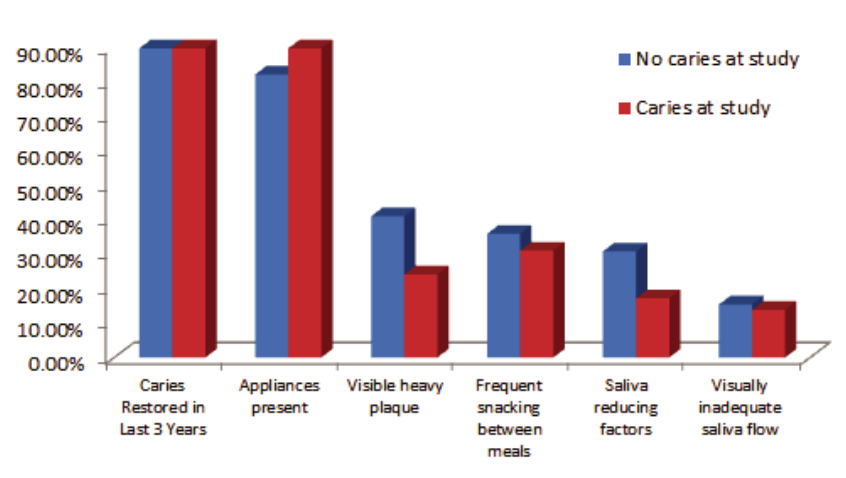

Figure 4. Prevalence of high-risk factors at study visit, by detectable caries on study day 
Moderate Risk Factors at Study Visit

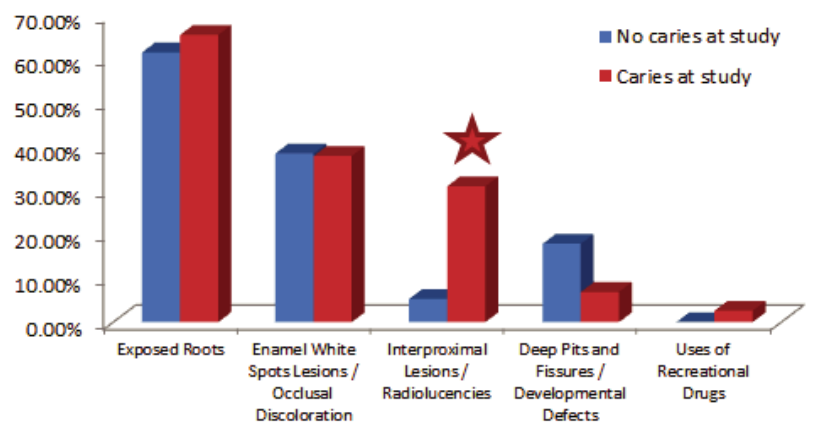

Figure 5. Prevalence of moderate-risk factors at study visit, by detectable caries on study day (red star denotes significance, $\mathbf{p}<0.05)$

\section{Protecting Factors at Study Visit}

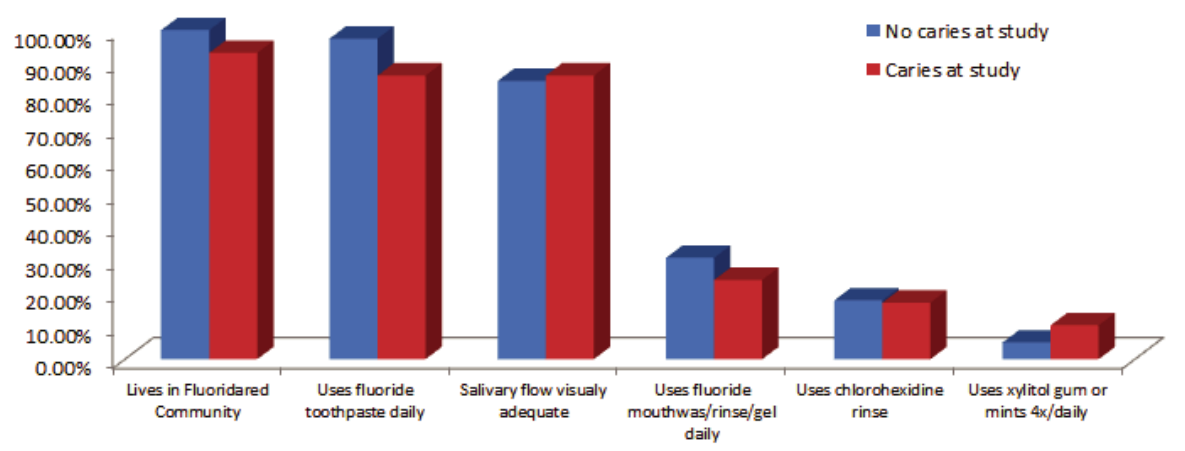

Figure 6. Prevalence of protective factors at study visit, by detectable caries on study day

Previous studies have analyzed how dental students perform risk assessments and how practitioners use these tools in practice, and the general consensus is that incorporating risk assessment protocols such as CAMBRA into predoctoral curricula is not without challenges. ${ }^{6,7,19,22}$ The same conclusion can be reached regarding the use of caries risk assessment and prevention techniques in practice. .,26,27 $^{-}$

The first step that determines risk evaluation is identifying the risk and protective factors; to the best of our knowledge, no one has previously reported the accuracy of dental students in performing this task. One study ${ }^{19}$ that enrolled eighty-nine patients who had a follow-up CRA (mean time after baseline $=14$ months, $\mathrm{SD}=4.5$ months) described only the possible association between different risk factors at the initial visit and presence of caries at the follow-up visit.

When we analyzed the relation of risk and protective factors at the study visit to the presence or absence of caries in dentin, our results showed that only incipient interproximal enamel lesions/radiolucencies were related to the presence of in-dentin 
Table 2. Mean number of risk and protective factors determined at initial CRA and at study visit, stratified by fluoride varnish (FV) receipt and detectable caries at study visit

\begin{tabular}{|c|c|c|c|c|c|c|}
\hline & & & & articipan & & \\
\hline Mean Number of Fact & ctors & $\begin{array}{c}\text { All } \\
N=68\end{array}$ & $\begin{array}{l}\mathrm{FV}+ \\
\mathrm{N}=30\end{array}$ & $\begin{array}{l}\mathrm{FV}- \\
\mathrm{N}=38\end{array}$ & $\begin{array}{c}\text { Caries + } \\
\mathrm{N}=29\end{array}$ & $\begin{array}{c}\text { Caries - } \\
N=38\end{array}$ \\
\hline High-risk factors & Initial & 2.5 & 2.7 & 2.4 & 2.7 & 2.4 \\
\hline & Study & 3.3 & 3.2 & 3.3 & 3.7 & 2.9 \\
\hline & p-value* & $<0.001$ & 0.052 & 0.001 & 0.03 & 0.027 \\
\hline All risk factors & Initial & 3.5 & 3.6 & 3.5 & 3.2 & 3.2 \\
\hline & Study & 4.6 & 4.5 & 4.6 & 4.2 & 4.2 \\
\hline & p-value* & $<0.001$ & 0.025 & 0.001 & 0.002 & 0.002 \\
\hline All protective factors & Initial & 2.8 & 3 & 2.6 & 2.7 & 2.7 \\
\hline & Study & 3.7 & 3.4 & 3.2 & 3.3 & 3.3 \\
\hline & p-value* & $<0.001$ & 0.103 & 0.012 & 0.012 & 0.012 \\
\hline
\end{tabular}

caries. This moderate-risk factor has been reported by others to have the highest odds ratio $(\mathrm{OR}=13.55)$ for the presence of in-dentin caries, even more so than factors classified in the high-risk category that have odds ratios between 0.99 to $2.75 .{ }^{19}$ This finding is easy to interpret because incipient interproximal lesions usually denote that the patient presents with previous caries activity that has been found to be correlated with development of future lesions. ${ }^{3}$

In our study, the fact that students underestimated both risk and protective factors at the initial visit compared with the study visit is of significance: the results show that students are not rigorous enough in documenting these factors and in determining the patient's risk. This concern is amplified by the fact that, at our dental school, the faculty member confirms the risk determination after reviewing the form with the patient and the student. These results suggest that further effort should be made to calibrate both students and faculty members and to identify the reasons why the risk factors are underestimated rather than overestimated, leading to a lower risk determination. One explanation may be that, on our risk assessment form, mentioning protective factors in a separate category may overemphasize their importance, so that students incorporate these protective factors in the risk-determination algorithm. In addition, the complexity of the form and the caries risk determination algorithm may pose challenges to both students and faculty members in the clinic.

The ADA's risk assessment form ${ }^{28}$ mentions only fluoride exposure as a protective factor, and even complete absence of exposure to fluoride makes only a minor contribution to increasing the risk. In order to be classified as high risk according to the ADA form, a patient has to accumulate ten risk points; the absence of fluoride exposure will contribute only one point. Use of fluorides has also been listed by dentists as one of the less influential caries-risk factors for treatment planning. ${ }^{27}$

It is of interest that the ADA form does not include use of Xylitol and/or Chlorhexidine in the protective factors category; this contradicts the guidelines for CAMBRA ${ }^{16-18}$ but is aligned with other studies that showed these materials having only marginal or insignificant value for caries risk reduction. ${ }^{4,19,29-31}$ Despite the ambiguity of the value of using Xylitol and Chlorhexidine, 73 percent of North American dental schools (including ours) still instruct patients to use antibacterials as a strategy for caries prevention. ${ }^{5}$ We suggest that, in light of the new evidence for the use of nonfluoride caries-preventive agents, ${ }^{31}$ the clinic protocols should be reviewed.

Our results show that no protective factor (fluoride, Xylitol, or Chlorhexidine) was related to the presence of caries at the study visit. Stratifying the patient pool either by exposure to fluoride varnish application before the study visit or by presence of caries at the study visit showed a similar pattern of risk and protective factors underestimation by dental students at the initial CRA visit.

According to our protocol as reflected by the CRA form, all sixty-eight enrolled patients were supposed to receive fluoride varnish following their 
initial visit, but only 44 percent of them did. This result agrees with previous studies from network practices that reported that only 57 percent of patients with CRA receive individualized caries prevention. ${ }^{27}$ Another study ${ }^{19}$ argued that the barrier to using antimicrobial therapy for mitigating caries risk in an educational setting is mainly financial and is related to the fact that preventive care is not eligible for reimbursement. Therefore, we can also assume that financial barriers played a significant role in fluoride varnish acceptance in our patient cohort.

The risk assessment underestimation leads to an increased number of false negatives when the CRS is determined: that is, patients who should be classified as high risk are classified as moderate risk. Failure to correctly classify these at-risk patients may lead to undertreatment and progression of the disease. To increase the sensitivity of the risk assessment, training and recalibration for students and faculty should be an ongoing process. Increasing the sensitivity of the CRA could lead to an increase in false-positive CRS, but "this will not result in any harm to the patient ... other than economical (cost of prevention)." ${ }^{21}$

The results and conclusions of this exploratory study should be interpreted with caution because the initial CRA data were collected by a large number of students as opposed to the CRA at the study visit, which was completed by two students supervised by two faculty members. Another limitation of the study is that, despite the statistically significant results, the number of patients enrolled in the study is relatively small. We also did not survey the patients in the study for the reasons of not receiving fluoride varnish.

Within these limitations, the following conclusions may be drawn:

1. Student dentists did not routinely use the information from the CRA form to arrive at the correct caries risk status.

2. The presence of untreated caries did not routinely prompt students to place patients in a high-risk category; similarly, multiple high-risk factors without current untreated caries also did not always prompt students to place patients in a high-risk category.

3. Among the factors examined during caries risk assessment at the study visit, only the presence of interproximal enamel lesions/radiolucencies was found to be associated with the presence of in-dentin caries at the time of assessment.

4. In this cohort of patients, fluoride varnish was underutilized as a treatment modality.

\section{REFERENCES}

1. Garcia RI, Sohn W. The paradigm shift to prevention and its relationship to dental education. J Dent Educ 2012;76(1):36-45.

2. Caries diagnosis and risk assessment: a review of preventive strategies and management. J Am Dent Assoc 1995;126(Suppl):1S-24S.

3. Fontana M, Zero DT. Assessing patients' caries risk. J Am Dent Assoc 2006;137(9):1231-9.

4. Autio-Gold JT, Tomar SL. Dental students' opinions and knowledge about caries management and prevention. J Dent Educ 2008;72(1):26-32.

5. Brown JP. A new curriculum framework for clinical prevention and population health, with a review of clinical caries prevention teaching in U.S. and Canadian dental schools. J Dent Educ 2007;71(5):572-8.

6. Calderón SH, Gilbert P, Zeff RN, Gansky SA, Featherstone JDB, Weintraub JA, Gerbert B. Dental students' knowledge, attitudes, and intended behaviors regarding caries risk assessment: impact of years of education and patient age. J Dent Educ 2007;71(11):1420-7.

7. Yorty JS, Walls AT, Wearden S. Caries risk assessment/ treatment programs in U.S. dental schools: an eleven-year follow-up. J Dent Educ 2011;75(1):62-7.

8. Bratthall D, Petersson GH. Cariogram: a multifactorial risk assessment model for a multifactorial disease. Community Dent Oral Epidemiol 2005;33(4):256-64.

9. Gonzalez CD, Okunseri C. Senior dental students' experience with cariogram in a pediatric dentistry clinic. J Dent Educ 2010;74(2):123-9.

10. Policy on use of a caries-risk assessment tool (CAT) for infants, children, and adolescents. Pediatr Dent 2008;30(7 Suppl):29-33 .

11. Nainar S, Straffon LH. Predoctoral dental student evaluation of American Academy of Pediatric Dentistry's cariesrisk assessment tool. J Dent Educ 2006;70(3):292-5.

12. Ismail AI, Sohn W, Tellez M, Amaya A, Sen A, Hasson $\mathrm{H}$, Pitts NB. The International Caries Detection and Assessment System (ICDAS): an integrated system for measuring dental caries. Community Dent Oral Epidemiol 2007;35(3):170-8

13. Diniz MB, Lima LM, Santos-Pinto L, Eckert GJ, Zandona AGF, Cordeiro RCL. Influence of the ICDAS e-learning program for occlusal caries detection on dental students. J Dent Educ 2010;74(8):862-8.

14. Featherstone JD, Adair SM, Anderson MH, Berkowitz RJ, Bird WF, Crall JJ, et al. Caries management by risk assessment: consensus statement, April 2002. J Calif Dent Assoc 2003;31(3):257-69.

15. Featherstone JDB, Domejean-Orliaguet S, Jenson L, Wolff M, Young D. Caries risk assessment in practice for age 6 through adult. J Calif Dent Assoc 2007;35(10):703.

16. Jenson L, Budenz A, Featherstone J, Ramos-Gomez F, Spolsky V, Young D. Clinical protocols for caries management by risk assessment. J Calif Dent Assoc 2007;35(10):714.

17. Spolsky VW, Black BP, Jenson L. Products: old, new, and emerging. J Calif Dent Assoc 2007;35(10):724.

18. Featherstone JDB. The science and practice of caries prevention. J Am Dent Assoc 2000;131(7):887. 
19. Doméjean-Orliaguet S, Gansky SA, Featherstone JD. Caries risk assessment in an educational environment. J Dent Educ 2006;70(12):1346-54.

20. Petersen PE, Bourgeois D, Ogawa H, Estupinan-Day S, Ndiaye C. The global burden of oral diseases and risks to oral health. Bull World Health Organ 2005;83(9):661-9.

21. Zero D, Fontana M, Lennon AM. Clinical applications and outcomes of using indicators of risk in caries management. J Dent Educ 2001;65(10):1126-32.

22. Fontana M, Zero D. Bridging the gap in caries management between research and practice through education: the Indiana University experience. J Dent Educ 2007;71(5):579-91.

23. Benn DK. Applying evidence-based dentistry to caries management in dental practice: a computerized approach. J Am Dent Assoc 2002;133(11):1543.

24. Beirne P, Clarkson JE, Worthington HV. Recall intervals for oral health in primary care patients. Cochrane Database Syst Rev 2007(4):CD004346.

25. Reisine ST, Psoter W. Socioeconomic status and selected behavioral determinants as risk factors for dental caries. J Dent Educ 2001;65(10):1009-16.
26. Riley JL III, Qvist V, Fellows JL, Rindal DB, Richman JS, Gilbert GH, Gordan VV. Dentists' use of caries risk assessment in children: findings from the dental PBRN. Gen Dent 2010;58(3):230.

27. Riley JL III, Gordan VV, Ajmo CT, Bockman H, Jackson MB, Gilbert GH. Dentists' use of caries risk assessment and individualized caries prevention for their adult patients: findings from The Dental Practice-Based Research Network. Community Dent Oral Epidemiol 2011;39:56473.

28. American Dental Association. Caries form (patients over 6 years). At: www.ada.org/sections/professional Resources/.../topics_caries_over6.d. Accessed: February 20, 2012.

29. Anusavice KJ. Present and future approaches for the control of caries. J Dent Educ 2005;69(5):538-54.

30. Bader JD, Shugars DA, Bonito AJ. A systematic review of selected caries prevention and management methods. Community Dent Oral Epidemiol 2001;29(6):399-411.

31. Rethman MP, Beltrán-Aguilar ED, Billings RJ, Burne RA, Clark M, Donly KJ, et al. Nonfluoride caries-preventive agents. J Am Dent Assoc 2011;142(9):1065-71. 